\title{
Preparation of Large Quantities of Powdered Enamel
}

\author{
JOHN J. HEFFERREN and WILLIAM I. HIGUCHI \\ Division of Chemistry, American Dental Association, Chicago, Illinois, and \\ School of Pharmacy, University of Michigan, Ann Arbor, Michigan
}

Powdered enamel of extracted human teeth has been used in the estimation of the activity of anticaries agents (S. D. Gershon, O. W. NeIditch, and R. H. C. LeE, Proc. Toilet Goods Ass., 28:14-17, 1957), as well as a number of studies with a direct or indirect relation to this activity. Correlation of results with different samples of enamel has been difficult because of the numerous variables. In order to minimize these variables, it has been desirable to carry out certain phases of a study with the same batch of enamel.

Rather than powder a large number of teeth by hand with a diamond mortar or other suitable instrument, various mechanical means of powdering teeth were explored, so that a relatively large sample of enamel could be obtained conveniently. An Abbe ball mill filled with flint stones ground the teeth to a very fine powder, but the grinding process was very slow. The particle size of the ground material was primarily coarse $(>60$ mesh) or very fine $(<325$ mesh): thus the desired graduation in particle size was not obtained. A Model M Fitz Mill, ${ }^{*}$ a stainlesssteel, blade-type hammer mill used extensively in pharmaceutical work, quickly ground the crowns into a variety of mesh sizes. In order to reduce the temperature build-up during the grinding operation and to increase the brittleness of the crowns, powdered dry ice, or preferably, liquid nitrogen was used to cool the crowns prior to grinding. This mixture was then added directly to the mill. The results of two runs with a 60 -mesh sizing screen on the hammer mill are given in the table.

Additional information is available on request to the authors. Received for publication July 20, 1964.

* W. J. Fitzpatrick Co., Chicago, Ill.
The 60-mesh sizing screen on the Fitz Mill gave the highest recovery of powder in the desired range of $<100,>200$ mesh. By appropriate selection of the sizing screen, it was possible within limits to alter the particle-size distribution. Further reduction in the particle size can be best obtained by passing the powdered material through a micronizer.

\section{RESULTS OF GRINDING ENAMEL WITH A 60-MESH SIZING SCREEN}

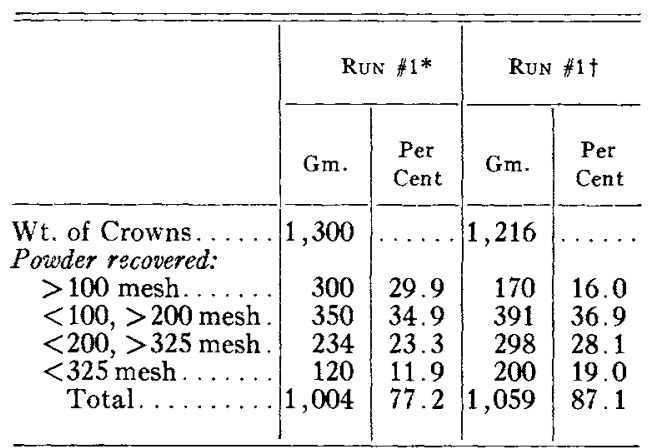

* Powdered dry ice used as coolant.

$\dagger$ Liquid nitrogen used as coolant.

The authors' thanks are offered to Dr. August Lemberger of the School of Pharmacy, University of Wisconsin, Dr. James Seitz of Parke, Davis \& Co., and Mr. Dewey A. Manion of the Fitzpatrick Co. for their helpful suggestions and to Michael Boles, Richard Edwards, Prafull Patel, and John Becker for their technical assistance. 